\title{
Age related morphometric changes of the glenoid labrum
}

\author{
Abduelmenem Alashkham $^{1-3}$ (D), Abdulrahman Alraddadi ${ }^{1,4}$ (D), Roger Soames ${ }^{2}$ (D) \\ 'Anatomy, School of Biomedical Sciences, Edinburgh Medical School, University of Edinburgh, Edinburgh, UK \\ ${ }^{2}$ Centre for Anatomy and Human Identification, University of Dundee, Dundee, UK \\ ${ }^{3}$ Human Anatomy Department, Faculty of Medicine, University of Zawia, Zawia, Libya \\ ${ }^{4}$ King Saud bin Abdulaziz University for Health Sciences, Riyadh, Saudi Arabia
}

\begin{abstract}
Objectives: Although the glenoid labrum is linked to glenohumeral joint stability, its anatomy remains controversial. This study aimed to investigate the shape, consistency of the glenoid labrum, and whether these and its thickness and depth are age related.

Methods: A total of 140 shoulders were dissected to expose the glenoid labrum. the shape and consistency of the glenoid labrum were assessed at a gross level. Measurements were taken of the labrum depth and thickness, using callipers, in the superior, anterior, inferior and posterior regions. ANOVA and chi-square tests were conducted to determine statistical significance, which was set at $\mathrm{p}<0.05$.

Results: The consistency of the superior half of the labrum was rubbery in $97.9 \%$ of specimens and firm in the remaining $2.1 \%$, whereas the entire inferior half was firm. There was a significant difference $(p=0.043)$ in the consistency of the superior half between males and females. The superior half was triangular in $95.7 \%$ of specimens, flat in $2.1 \%$ and flat to triangular in $2.1 \%$, whereas the shape of the inferior half was rounded in $99.3 \%$ of specimens and flat in $0.7 \%$. The labrum was observed to be thicker in younger individuals, with the differences being significant superiorly $(p=0.011)$, anteriorly $(p=0.050)$, inferiorly $(p=0.001)$ and posteriorly $(p=0.047)$. It was also observed to be deeper in younger individuals, but only significantly so superiorly $(\mathrm{p}=0.044)$.
\end{abstract}

Conclusion: Labrum thickness and depth significantly decreased with increasing age, suggesting that these observations could be age-related.

Keywords: glenoid; labrum; morphometry; scapula; shoulder

Anatomy 2020;14(3):177-184 (2)20 Turkish Society of Anatomy and Clinical Anatomy (TSACA)

\section{Introduction}

The glenoid fossa is deepened by the glenoid labrum, which is located at the junction between the fibrous capsule of the glenohumeral joint and glenoid fossa. ${ }^{[1]}$ Several studies describe the labrum as being variable in shape and size, being rounded, triangular, undersized, blunt-tipped, crescentic, flat, cleaved, notched or absent..$^{[2-8]}$

The precise function of the glenoid labrum is still unknown. Several studies agree that it provides stability to the glenohumeral joint, but the methods used, as well as the observations and interpretation about how the glenoid labrum contributes to stability differ. The glenoid labrum has been reported to increase the width and depth of the glenoid fossa by about $4 \mathrm{~mm} .^{[5,9,10]}$ Others with the opinion that the glenoid labrum effectively increases the depth of the glenoid socket by $9 \mathrm{~mm}$ superoinferiorly and $5 \mathrm{~mm}$ anteroposteriorly contributing to the overall circumferential depth by $50 \%$. Tears of the anterior glenoid labrum, such as in Bankart lesions, decrease glenoid socket depth

This study bas been presented at the Winter Meeting of the British Association of Clinical Anatomists (BACA), 13th December 2018, Northumbria University, Newcastle, UK. 
between 2.4 - $5 \mathrm{~mm}$ anteroposteriorly and could lead to glenohumeral joint instability. ${ }^{[1]}$

The concavity compression stabilization of the glenohumeral joint is enhanced by increasing both the magnitude of the compressive load, as a result of dynamic muscle contraction, and glenoid cavity depth. The existence of an intact glenoid labrum is therefore important for concavity compression, as well as scapulohumeral balance, which also leads to further stabilization of the glenohumeral joint. ${ }^{[12]}$ The effect of the glenoid labrum and movement of the arm on stability of the glenohumeral joint has been quantified using a concavity-compression technique; the average glenoid labrum contribution to stability being $10 \% .^{[13]}$ Others believe the glenoid labrum extends the articular surface. ${ }^{[9,14]}$ Therefore, loss of the anteroinferior aspects of the glenoid labrum leads to a decrease in the contact surface area from $7 \%$ to $15 \%$ compared to normal shoulders, and an increase in contact pressure from $8 \%$ to $20 \% .^{[15]}$

All the histological evaluated criteria of the labrum, including grading of tears, structural defects, cell number, and vascularity, showed a highly significant positive relationship with age. ${ }^{[16]}$ Others with the opinion that variation of labrum size is due to aging. ${ }^{[1,17]}$ It was observed that individuals in their fifth decade at the time of death, that the glenoid labrum was thin and virtually absent. ${ }^{[1]}$ One study applied an anterior force at different degrees of external rotation and abduction and observed that the radial thickness and tensile modulus of the glenoid labrum varied, for instance the peak strains of a thinning glenoid labrum at the axillary region increase at $60^{\circ}$ external rotation, which goes some way to explain the aetiology of thinning of the glenoid labrum with age. ${ }^{[17]}$ Others reported no significant correlation between the size of the glenoid labrum and the underlying glenoid bone, adding that if one region of the glenoid labrum is large other regions also tend to be larger. It was also noticed that the anterior and inferior aspects of the glenoid labrum are the largest, suggesting that they could contribute to glenohumeral joint stability. ${ }^{[18]}$

Although the important function of the glenoid labrum in shoulder joint stability is recognised, its gross morphometric changes in relation to age are seldom reported. The purpose of the current study was to investigate the shape, consistency and mode of attachment of the glenoid labrum, and whether these and it's the thickness and depth were related to age.

\section{Materials and Methods}

A total of 220 cadaveric shoulders from 58 males and 59 females, with a median age of 82 (range 53-102) years were obtained from the Centre for Anatomy and Human Identification University of Dundee in accordance with the Human Tissue Act 2006. Macroscopically normal shoulder joints were selected for this study - i.e., shoulders with signs of previous surgery, fracture or pathology were excluded.

Consequently, 140 specimens (30 male and 40 female cadavers: an average age 81.5 years) were recruited for this study. All shoulders were carefully dissected to expose the glenoid fossa with the labrum attached. The shape and consistency of the glenoid labrum were examined grossly and divided into superior (9-3 o'clock) and inferior (39 o'clock) halves as suggested by Prodromos et al. ${ }^{[1]}$ (Figure 1) Measurements were taken of labrum depth (defined as the distance from the glenoid edge to the anterior edge of the glenoid labrum) and thickness (defined as the distance from the outer to the inner edges of the glenoid labrum) in the superior, anterior, inferior and posterior regions: thickness and depth labrum were taken in millimetres using Vernier digital callipers. ${ }^{[19]}$

Specimens were stratified according to their age into these groups: Group 1, aged 50-55 years old; Group 2, aged 55-60 years old; Group 3, aged 60-65 years old; Group 4, aged 65-70 years old; Group 5, aged 70-75 years old; Group 6, aged 75-80 years old; Group 7, aged 80-85 years old; Group 8, aged 85-90 years old; and Group 9, aged $>90$ years old. The age groups, side, consistency, shape, and both the thickness and depth of the glenoid labrum were double-entered into Statistical Package for Social Sciences (SPSS Version 21, Armonk; NY, USA). Kruskal-Wallis one way analysis of variance of ranks, ANOVA and Chi-square tests were conducted to determine statistical significance, which was set at $\mathrm{p}<0.05$. The repeatability and the reliability of the taken measurement

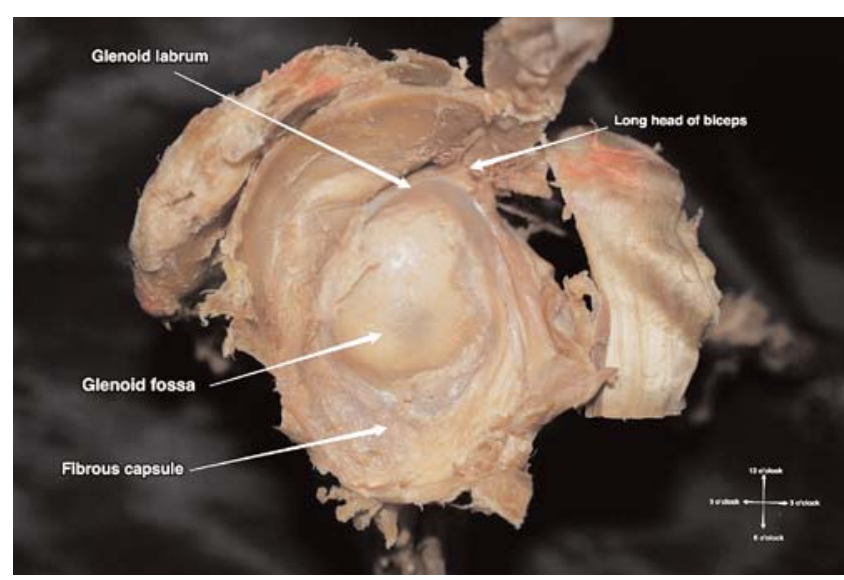

Figure 1. Right shoulder showing the glenoid labrum, glenoid fossa, fibrous capsule and long head of biceps brachii muscle. 
were assessed by randomly selecting shoulders from those studied. Three measurements were taken on a three separate occasions by the researcher, while two other individuals took the measurements on two other occasions. Kruskal-Wallis one way analysis of variance of ranks showed that there was no difference for a single observer between the same measurements taken on separate occasions $(\mathrm{p}<0.504)$; there was also no difference in measurements taken by different observers $(\mathrm{p}<0.759)$. These results indicate that the measurement methodology that was used is reliable and repeatable.

\section{Results}

The total number of shoulder specimens was 140 from 30 male and 40 female cadavers, with a mean age of $81.5 \pm$ 9.81 years.

The consistency of the superior half of the labrum was rubbery in $97.9 \%(n=137)$ of specimens and firm in the remaining $2.1 \%(n=3)$, while the entire inferior half was firm. Based on age the consistency of the superior and inferior half of the labrum was variable, but not significant. Based on side and sex a difference in the consistency of the superior half of the labrum between males and females was observed $(\mathrm{p}=0.043)$. No difference was observed in consistency between side.

The superior half of the glenoid labrum was triangular in $95.7 \%(\mathrm{n}=134)$, flat in $2.1 \%(\mathrm{n}=3)$ and flat to triangular in $2.1 \%(n=3)$ of specimens, while the shape of the inferior half was rounded in $99.3 \%(n=139)$ and flat in $0.7 \%$ $(n=1)$. Based on age, sex and side the shape of the glenoid labrum varied, but not significantly so.

Based on age groups, the thickness of the glenoid labrum varies, and significantly associated with age. There were differences in thickness between age groups, being thicker in younger in all the regions (Table 1, Figure 2). The differences were significant superiorly $(\mathrm{p}=0.011)$, anteriorly $(\mathrm{p}=0.050)$, inferiorly $(\mathrm{p}=0.001)$, and posteriorly $(\mathrm{p}=0.047)$. The depth of the glenoid labrum was also variable. There was a difference in depth between the age groups (Table 2, Figure 3), being deeper in younger in all the regions. The difference was significant superiorly $(\mathrm{p}=0.044)$, but not anteriorly, inferiorly or posteriorly $(\mathrm{p}=0.232, \mathrm{p}=0.760$ and $\mathrm{p}=0.84$ respectively).

For thickness and depth of the superior aspect of the glenoid labrum, the post-hoc LSD revealed that (1) the thickness of the glenoid labrum of Group 9 (mean thickness: $5.66 \mathrm{~mm}$ ) was significantly thinner than Group 5 (mean thickness: $6.59 \mathrm{~mm})(\mathrm{p}=0.004)$ and Group 6 (mean thickness: $6.54 \mathrm{~mm})(\mathrm{p}=0.002)$; (2) the thickness of the glenoid labrum of Group 8 (mean thickness: $5.71 \mathrm{~mm}$ ) was significantly thinner than Group 5 (mean thickness: 6.59 $\mathrm{mm})(\mathrm{p}=0.010)$ and Group 6 (mean thickness: $6.54 \mathrm{~mm})$ $(\mathrm{p}=0.007)$; (3) and the thickness of the glenoid labrum of Group 7 (mean thickness: $5.75 \mathrm{~mm}$ ) was significantly thinner than Group 5 (mean thickness: $6.59 \mathrm{~mm})(\mathrm{p}=0.014)$ and Group 6 (mean thickness: $6.54 \mathrm{~mm})(\mathrm{p}=0.010)$; (4) the depth of the glenoid labrum of Group 8 (mean depth: 6.12 $\mathrm{mm}$ ) was significantly shallower than Group 3 (mean depth: $5.11 \mathrm{~mm})(\mathrm{p}=0.021)$; (5) the depth of the glenoid labrum of Group 7 (mean depth: $5.76 \mathrm{~mm}$ ) was significantly shallower than Group 5 (mean depth: $6.41 \mathrm{~mm}$ ) $(\mathrm{p}=0.029) ;(6)$ the depth of the glenoid labrum of Group 6 (mean depth: $5.80 \mathrm{~mm}$ ) was significantly shallower than Group 5 (mean depth: $6.41 \mathrm{~mm})(\mathrm{p}=0.036)$; (7) the depth of the glenoid labrum of Group 5 (mean depth: $6.41 \mathrm{~mm}$ ) was significantly shallower than Group 3 (mean depth: $5.11 \mathrm{~mm})(\mathrm{p}=0.004)$; and (8) the depth of the glenoid labrum of Group 3 (mean depth: $5.1 \mathrm{~mm}$ ) was significantly shallower than Group 2 (mean depth: $7 \mathrm{~mm})(\mathrm{p}=0.016)$.

For thickness and depth of the anterior aspect of the glenoid labrum, the post-hoc LSD revealed that (1) the thickness of the glenoid labrum of Group 8 (mean thickness: $3.69 \mathrm{~mm}$ ) was significantly thinner that Group 4 (mean thickness: $4.76 \mathrm{~mm})(\mathrm{p}=0.043)$ and Group 6 (mean thickness: $4.36 \mathrm{~mm})(\mathrm{p}=0.16)$; (2) the thickness of the glenoid labrum of Group 7 (mean thickness: $3.79 \mathrm{~mm}$ ) was significantly thinner that Group 6 (mean thickness: 4.36 $\mathrm{mm})(\mathrm{p}=0.039)$; (3) the thickness of the glenoid labrum of Group 6 (mean thickness: $4.36 \mathrm{~mm}$ ) was significantly thinner that Group 3 (mean thickness: $3.44 \mathrm{~mm})(\mathrm{p}=0.036)$; (4) the thickness of the glenoid labrum of Group 4 (mean thickness: $4.76 \mathrm{~mm}$ ) was significantly thinner that Group 3 (mean thickness: $3.44 \mathrm{~mm})(\mathrm{p}=0.036)$; and (5) the depth of the glenoid labrum of Group 7 (mean depth: $3.34 \mathrm{~mm}$ ) was significantly shallower than Group 4 (mean depth: $4.16 \mathrm{~mm})(\mathrm{p}=0.038)$ and Group 6 (mean depth: $3.79 \mathrm{~mm})$ $(\mathrm{p}=0.030)$.

For the thickness and depth of the inferior aspect of the glenoid labrum, the post-hoc LSD revealed that (1) the thickness of the glenoid labrum of Group 9 (mean thickness: $5.08 \mathrm{~mm}$ ) was significantly thinner that Group 4 (mean thickness: $7.67 \mathrm{~mm})(\mathrm{p}=0.0001)$; (2) the thickness of the glenoid labrum of Group 8 (mean thickness: 4.78 $\mathrm{mm}$ ) was significantly thinner that Group 4 (mean thickness: $7.67 \mathrm{~mm})(\mathrm{p}=0.0001)$; (3) the thickness of the glenoid labrum of Group 7 (mean thickness: $5.15 \mathrm{~mm}$ ) was significantly thinner that Group 4 (mean thickness: $7.67 \mathrm{~mm}$ ) $(p=0.0001)$; (4) the thickness of the glenoid labrum of Group 6 (mean thickness: $5.15 \mathrm{~mm}$ ) was significantly thinner that Group 4 (mean thickness: $7.67 \mathrm{~mm})(\mathrm{p}=0.0001)$; and (5) the thickness of the glenoid labrum of Group 5 
Table 1

The thickness of glenoid labrum $(\mathrm{mm})$ with respect to age.

\begin{tabular}{|c|c|c|c|c|c|}
\hline & Group & Mean \pm SD & Minimum & Maximum & p-value \\
\hline \multirow{10}{*}{ Superior region } & 1 & $5.54 \pm 0.523$ & 5.17 & 5.91 & 0.011 \\
\hline & 2 & $6.52 \pm 2.375$ & 4.84 & 8.20 & \\
\hline & 3 & $6.01 \pm 0.898$ & 4.45 & 7.06 & \\
\hline & 4 & $6.28 \pm 0.886$ & 5.50 & 7.17 & \\
\hline & 5 & $6.59 \pm 1.265$ & 4.42 & 8.60 & \\
\hline & 6 & $6.54 \pm 1.002$ & 5.10 & 8.78 & \\
\hline & 7 & $5.75 \pm 0.982$ & 3.88 & 7.37 & \\
\hline & 8 & $5.71 \pm 1.268$ & 3.12 & 8.53 & \\
\hline & 9 & $5.66 \pm 0.923$ & 2.90 & 7.67 & \\
\hline & Total & $6.01 \pm 1.121$ & 2.90 & 8.78 & \\
\hline \multirow[t]{10}{*}{ Anterior region } & 1 & $3.66 \pm 1.131$ & 2.86 & 4.46 & 0.050 \\
\hline & 2 & $4.97 \pm 0.254$ & 4.79 & 5.15 & \\
\hline & 3 & $3.44 \pm 0.562$ & 2.85 & 4.16 & \\
\hline & 4 & $4.76 \pm 1.008$ & 3.70 & 5.93 & \\
\hline & 5 & $3.79 \pm 0.887$ & 2.04 & 5.41 & \\
\hline & 6 & $4.36 \pm 1.472$ & 1.50 & 7.91 & \\
\hline & 7 & $3.79 \pm 0.841$ & 2.12 & 5.48 & \\
\hline & 8 & $3.69 \pm 0.769$ & 2.41 & 5.35 & \\
\hline & 9 & $3.88 \pm 0.724$ & 2.78 & 5.62 & \\
\hline & Total & $3.93 \pm 0.984$ & 1.50 & 7.91 & \\
\hline \multirow[t]{10}{*}{ Inferior region } & 1 & $6.14 \pm 0.855$ & 5.54 & 6.75 & 0.001 \\
\hline & 2 & $5.88 \pm 0.650$ & 5.42 & 6.34 & \\
\hline & 3 & $4.40 \pm 0.826$ & 3.27 & 5.41 & \\
\hline & 4 & $7.67 \pm 0.629$ & 6.65 & 8.12 & \\
\hline & 5 & $5.14 \pm 1.032$ & 3.26 & 7.49 & \\
\hline & 6 & $5.15 \pm 1.392$ & 2.13 & 8.83 & \\
\hline & 7 & $5.15 \pm 0.982$ & 2.79 & 7.18 & \\
\hline & 8 & $4.78 \pm 0.867$ & 2.52 & 6.32 & \\
\hline & 9 & $5.08 \pm 0.744$ & 4.13 & 6.78 & \\
\hline & Total & $5.13 \pm 1.091$ & 2.13 & 8.83 & \\
\hline \multirow[t]{10}{*}{ Posterior region } & 1 & $3.78 \pm 0.084$ & 3.72 & 3.84 & 0.047 \\
\hline & 2 & $5.49 \pm 0.459$ & 5.17 & 5.82 & \\
\hline & 3 & $3.66 \pm 0.469$ & 3.15 & 4.54 & \\
\hline & 4 & $5.52 \pm 1.132$ & 4.36 & 6.68 & \\
\hline & 5 & $4.47 \pm 0.984$ & 2.66 & 5.96 & \\
\hline & 6 & $4.44 \pm 1.008$ & 2.83 & 6.77 & \\
\hline & 7 & $4.24 \pm 0.982$ & 2.81 & 6.60 & \\
\hline & 8 & $4.29 \pm 1.052$ & 2.89 & 6.99 & \\
\hline & 9 & $4.04 \pm 1.006$ & 2.08 & 6.40 & \\
\hline & Total & $4.29 \pm 1.015$ & 2.08 & 6.99 & \\
\hline
\end{tabular}

Group 1: 50-55 years old; Group 2: 55-60 years old; Group 3: 60-65 years old; Group 4: 65-70 years old; Group 5: 70-75 years old; Group 6: 75-80 years old; Group 7: aged 80-85 years old; Group 8: aged 85-90 years old; and Group 9: aged $>90$ years old.

(mean thickness: $5.14 \mathrm{~mm}$ ) was significantly thinner that Group 4 (mean thickness: $7.67 \mathrm{~mm})(\mathrm{p}=0.0001)$. No significant difference was noticed in the glenoid labrum depth between the groups.

For the thickness and depth of posterior aspect of the glenoid labrum, the post-hoc LSD revealed that (1) the thickness of the glenoid labrum of Group 9 (mean thickness: $4.04 \mathrm{~mm}$ ) was significantly thinner that Group 4 (mean thickness: $5.52 \mathrm{~mm})(\mathrm{p}=0.006)$ and Group 2 (mean thickness: $5.49 \mathrm{~mm})(\mathrm{p}=0.047)$; (2) the thickness of the glenoid labrum of Group 8 (mean thickness: $4.29 \mathrm{~mm}$ ) was significantly thinner that Group 4 (mean thickness: 5.52 $\mathrm{mm})(\mathrm{p}=0.024)$; (3) the thickness of the glenoid labrum of Group 7 (mean thickness: $4.24 \mathrm{~mm}$ ) was significantly thinner that Group 4 (mean thickness: $5.52 \mathrm{~mm})(\mathrm{p}=0.019)$; (4) the thickness of the glenoid labrum of Group 6 (mean thickness: $4.44 \mathrm{~mm}$ ) was significantly thinner that Group 4 (mean thickness: $5.52 \mathrm{~mm})(\mathrm{p}=0.046)$; (5) the thickness of the glenoid labrum of Group 4 (mean thickness: 5.52 $\mathrm{mm}$ ) was significantly thinner that Group 3 (mean thickness: $3.66 \mathrm{~mm})(\mathrm{p}=0.004)$; (6) the thickness of the glenoid labrum of Group 3 (mean thickness: $3.66 \mathrm{~mm}$ ) was signif- 
Table 2

The depth glenoid labrum $(\mathrm{mm})$ with respect to age.

\begin{tabular}{|c|c|c|c|c|c|}
\hline & Groups & Mean $\pm S D$ & Minimum & Maximum & p-value \\
\hline \multirow[t]{10}{*}{ Superior region } & 1 & $7.38 \pm 0.989$ & 6.68 & 8.08 & 0.044 \\
\hline & 2 & $7.00 \pm 0.318$ & 6.78 & 7.23 & \\
\hline & 3 & $5.11 \pm 1.024$ & 4.07 & 6.80 & \\
\hline & 4 & $5.48 \pm 1.352$ & 4.05 & 7.30 & \\
\hline & 5 & $6.41 \pm 1.358$ & 4.05 & 8.73 & \\
\hline & 6 & $5.80 \pm 0.699$ & 4.32 & 7.51 & \\
\hline & 7 & $5.76 \pm 0.983$ & 3.36 & 7.08 & \\
\hline & 8 & $6.12 \pm 0.732$ & 4.52 & 7.22 & \\
\hline & 9 & $5.90 \pm 0.912$ & 4.19 & 7.57 & \\
\hline & Total & $5.95 \pm 0.985$ & 3.36 & 8.73 & \\
\hline \multirow[t]{10}{*}{ Anterior region } & 1 & $3.83 \pm 0.035$ & 3.81 & 3.86 & 0.232 \\
\hline & 2 & $4.22 \pm 1.817$ & 2.94 & 5.51 & \\
\hline & 3 & $3.44 \pm 0.538$ & 2.57 & 3.96 & \\
\hline & 4 & $4.16 \pm 0.157$ & 3.95 & 4.30 & \\
\hline & 5 & $3.59 \pm 0.488$ & 2.77 & 4.46 & \\
\hline & 6 & $3.79 \pm 1.072$ & .72 & 5.44 & \\
\hline & 7 & $3.34 \pm 0.657$ & 2.23 & 4.49 & \\
\hline & 8 & $3.58 \pm 0.615$ & 2.35 & 4.86 & \\
\hline & 9 & $3.69 \pm 0.544$ & 2.34 & 4.75 & \\
\hline & Total & $3.63 \pm 0.716$ & .72 & 5.51 & \\
\hline \multirow{10}{*}{ Inferior region } & 1 & $4.00 \pm 0.820$ & 3.42 & 4.58 & 0.760 \\
\hline & 2 & $3.80 \pm 0.275$ & 3.61 & 4.00 & \\
\hline & 3 & $3.42 \pm 0.206$ & 3.18 & 3.69 & \\
\hline & 4 & $3.99 \pm 0.462$ & 3.38 & 4.40 & \\
\hline & 5 & $3.70 \pm 0.534$ & 3.16 & 5.00 & \\
\hline & 6 & $3.88 \pm 0.729$ & 1.72 & 5.43 & \\
\hline & 7 & $3.62 \pm 0.536$ & 2.62 & 4.53 & \\
\hline & 8 & $3.72 \pm 0.738$ & 2.14 & 5.36 & \\
\hline & 9 & $3.73 \pm 0.739$ & 2.07 & 4.84 & \\
\hline & Total & $3.73 \pm 0.650$ & 1.72 & 5.43 & \\
\hline \multirow[t]{10}{*}{ Posterior region } & 1 & $3.82 \pm 0.487$ & 3.48 & 4.17 & 0.840 \\
\hline & 2 & $4.79 \pm 1.315$ & 3.86 & 5.72 & \\
\hline & 3 & $3.35 \pm 0.255$ & 3.16 & 3.75 & \\
\hline & 4 & $4.26 \pm 0.441$ & 3.70 & 4.71 & \\
\hline & 5 & $3.91 \pm 0.686$ & 2.70 & 5.40 & \\
\hline & 6 & $3.92 \pm 0.597$ & 3.13 & 5.22 & \\
\hline & 7 & $3.90 \pm 0.639$ & 2.66 & 5.22 & \\
\hline & 8 & $3.67 \pm 0.752$ & 2.46 & 5.03 & \\
\hline & 9 & $3.80 \pm 0.515$ & 2.83 & 4.88 & \\
\hline & Total & $3.84 \pm 0.634$ & 2.46 & 5.72 & \\
\hline
\end{tabular}

Group 1: 50-55 years old; Group 2: 55-60 years old; Group 3: 60-65 years old; Group 4: 65-70 years old; Group 5: 70-75 years old; Group 6: 75-80 years old; Group 7: aged 80-85 years old; Group 8: aged 85-90 years old; and Group 9: aged >90 years old.

icantly thinner that Group 2 (mean thickness: $5.49 \mathrm{~mm}$ ) $(\mathrm{p}=0.026) ;(7)$ the depth of the glenoid labrum of Group 9 (mean depth: $3.80 \mathrm{~mm}$ ) was significantly shallower than Group 2 (mean depth: $4.79 \mathrm{~mm})(\mathrm{p}=0.032)$; (8) the depth of the glenoid labrum of Group 8 (mean depth: $3.67 \mathrm{~mm}$ ) was significantly shallower than Group 2 (mean depth: $4.79 \mathrm{~mm})(\mathrm{p}=0.017)$; (9) the depth of the glenoid labrum of Group 6 (mean: $3.92 \mathrm{~mm}$ ) was significantly shallower than Group 3 (mean depth: $3.35 \mathrm{~mm})(\mathrm{p}=0.046) ;(10)$ the depth of the glenoid labrum of Group 4 (mean depth: 4.26 $\mathrm{mm}$ ) was significantly shallower than Group 3 (mean depth: $3.35 \mathrm{~mm})(\mathrm{p}=0.025)$; and (11) the depth of the glenoid labrum of Group 3 (mean depth: $3.35 \mathrm{~mm}$ ) was significantly shallower than Group 2 (mean depth: $4.79 \mathrm{~mm}$ ) $(\mathrm{p}=0.006)$.

\section{Discussion}

As all the evaluation criteria of the glenoid labrum, including grading of tears, structural defects, cell number, and vascularity, showed a highly significant positive relationship with age. ${ }^{[16]}$ Changes in the gross morphometry of the 


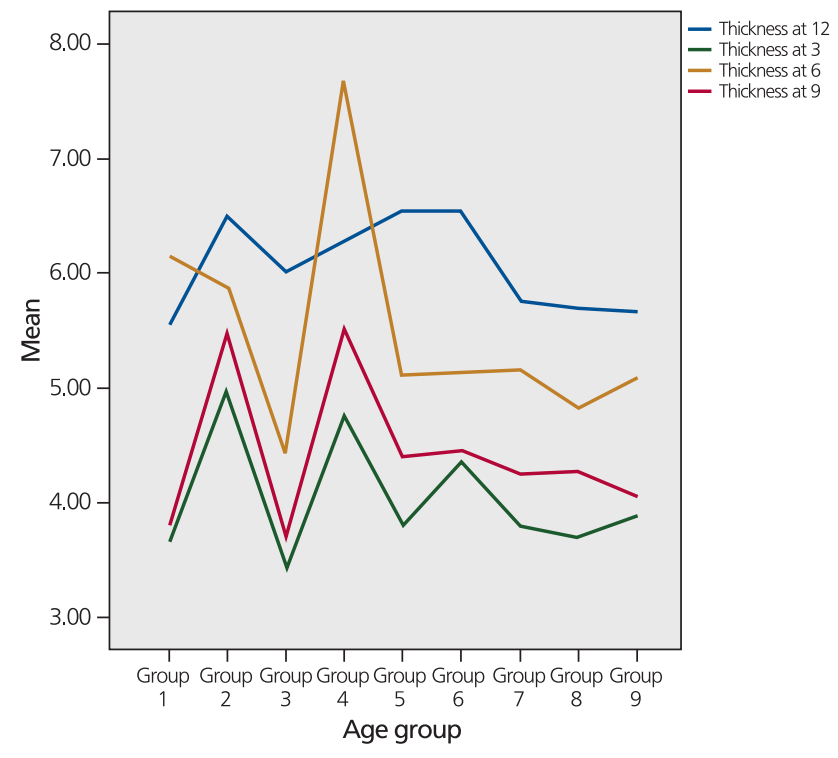

Figure 2. Glenoid labrum thickness according to age.

labrum in relation to age is seldom reported. Therefore, the current study was undertaken to investigate the correlation between glenoid labral thickness and depth with age. Labral thickness in the superior, anterior, inferior and posterior aspects of the glenoid labrum were significantly associated with age. Labral depth was significantly associated with age in the superior and anterior regions. The underlying reasons are unknown, but some studies suggest that the variation in size is due to aging. ${ }^{[1,17]}$ Drury et al. ${ }^{[17]}$ applied an anterior force at different degrees of external rotation and abduction and observed that radial thickness and tensile modulus of the glenoid labrum varied, for example the peak strains of a thinning glenoid labrum in the axillary region increase at 600 external rotation, which goes some way to explain the aetiology of thinning of the glenoid labrum with age. ${ }^{[17]}$

The elastic modulus and stiffness of the glenoid labrum have been evaluated, with significant differences between the superior and inferior aspects, but were similar when comparing all superior or all inferior labrum. ${ }^{[3]}$ In contrast, Smith et al ${ }^{[2]}$ reported that the mean elastic modulus and yield stress of the glenoid labrum are 22.8 and 2.5 respectively, which were both lower in the anterosuperior aspect of the glenoid labrum compared to the anteroinferior. Prodromos et al. ${ }^{[1]}$ reported regional differences in labral consistency. This is in line with the observations of the current study in which the consistency of the superior half of the labrum was rubbery in $97.9 \%$ and firm in $2.1 \%$ of specimens, with a significant difference between males and females, whereas the entire inferior half was firm.

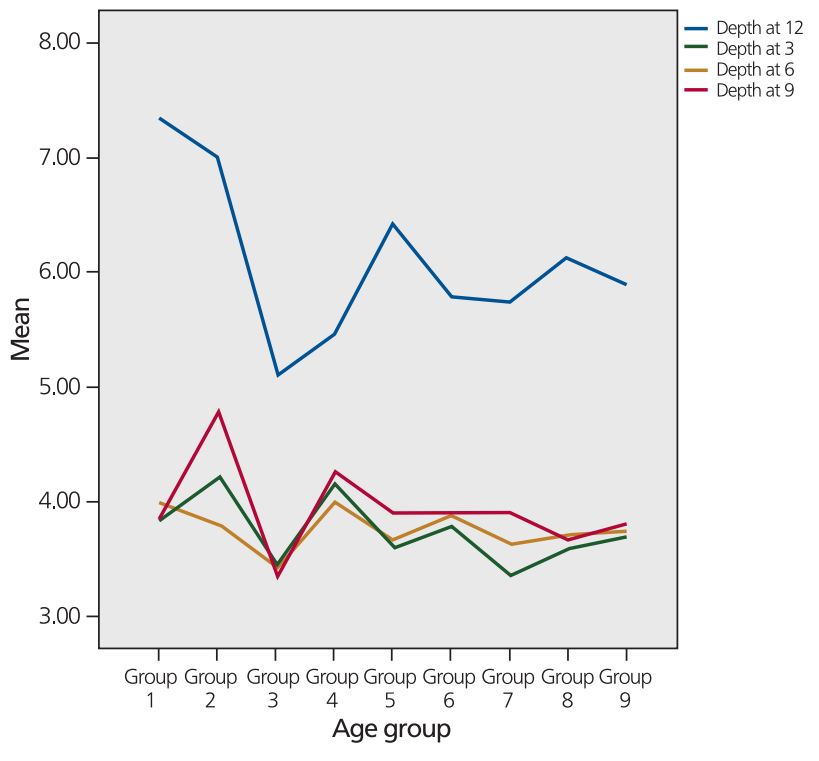

Figure 3. Glenoid labrum depth according to age.

The shape of the glenoid labrum has been variably described in the literature. According to Smith et al ${ }^{[9]}$ and Soames and Palastanga ${ }^{[10]}$ it has triangular cross-section with the base attached circumferentially to the rim of the glenoid fossa. De Maeseneer et al. ${ }^{[5]}$ reported that the labrum is usually rounded or triangular, with the appearance of its anterior part being triangular, undersized, blunt-tipped or crescentic. These studies describe the labrum as a whole, with differences in shape between regions not being considered. In contrast, Cooper et al. ${ }^{[6]}$ reported regional differences stating that the anterosuperior region is triangular and the inferior region rounded. Earlier McNeish and Callaghan ${ }^{[2]]}$ observed the anterior part of the glenoid labrum to be cleaved, notched or redundant, while both Haynor and Shuman ${ }^{[7]}$ and Rafii et al. ${ }^{[8]}$ reported the posterior labrum as being rounded and the anterior either rounded or triangular. Other studies have commented that the shape of the glenoid labrum is not regionally consistent; however, the shape in each region differs among studies. Park et al. ${ }^{[2]}$ observed the labrum as being triangular anteriorly in $64 \%$ and posteriorly in $47 \%$, rounded anteriorly in $17 \%$ and posteriorly in $33 \%$, flat anteriorly in $2 \%$ and posteriorly in $17 \%$, cleaved in $11 \%$, and notched in $3 \%$. The labrum was reported by Longo et al. ${ }^{[2]}$ to be triangular anteriorly and posteriorly in $50 \%$, crescent-shaped in $14 \%$, rounded in $14 \%$, flat in $8 \%$, cleaved-shaped in $2 \%$ and absent posteriorly in $6 \%$. In contrast, the current study found the superior half of the glenoid labrum as being triangular in $95.7 \%$, flat in $2.1 \%$ and flat to triangular in $2.1 \%$ of specimens, whereas 
the shape of the inferior half was rounded in $99.3 \%$ and flat in $0.7 \%$ of specimens. To some extent these observations agree with Cooper et al., ${ }^{[6]}$ but disagree with Rafii et al. ${ }^{[8]} \mathrm{McNiesh}$ and Callaghan, ${ }^{[21]}$ Longo et al. ${ }^{[2]}$ and Park et al. ${ }^{[2]}$ The difference in observations between the current and other studies may be due to: (1) other studies were based on MRI and double contrast CT arthrograms, while the current study used gross dissection which is more accurate and reliable, (2) patients in other studies suffered from glenohumeral instability in which the shape of glenoid labrum could be changed, and (3) sex, race and age could have a significant association with the shape of the glenoid labrum. In the current study, severe osteoarthritic changes were associated with a flattened glenoid labrum: such shape changes were not associated with aging. Cleaved, notched, redundant or an absent posterior aspect of the glenoid labrum were not observed. A major advantage of the current study was the sample size (140 shoulders) and gross dissection: these two elements enhance the investigation decreasing the risk of bias.

One of the limitations of the current study is the age of the study group. Therefore, further study in younger individuals is recommended. The other limitation is to investigate the correlation between the histological changes of the glenoid labrum with age, side and sex. The third limitation to study the association between the glenoid labrum thickness, depth, consistency and shape with glenohumeral joint instability.

\section{Conclusion}

The current study is the first to correlate glenoid labrum thickness, depth, consistency and shape with age, sex and side. Labrum thickness in the superior, anterior, inferior and posterior aspects of the glenoid labrum were significantly associated with age. Labral depth was also observed to become significantly associated with age in the superior and anterior regions. There was no association between the shape of glenoid labrum and age, sex and side. However, there were differences in consistency of the superior half of the glenoid labrum between males and females. The association between the glenoid labrum thickness, depth, consistency and shape with glenohumeral joint instability is still unknown and further studies are therefore recommended.

\section{Acknowledgments}

The authors would like to express their sincere gratitude to the donors and their families. Special thanks to the staff of Anatomy at University of Zawia and Centre for Anatomy and Human Identification, University of Dundee.

\section{Conflict of Interest}

The authors declare no conflict of interest.

\section{Author Contributions}

AMA, ARA, RS: collection and processing of material; AMA: data analysis and interpretation; AMA: writing manuscript; RS: Supervision and proofreading the manuscript.

\section{Ethics Approval}

The specimens were obtained from Centre for Anatomy and Human Identification. All studies carried out in the Centre for Anatomy and Human Identification are regulated and approved by the Anatomy Scotland Act (2006).

\section{Funding}

The authors received no financial support for this study.

\section{References}

1. Prodromos CC, Ferry JA, Schiller AL, Zarins B. Histological studies of the glenoid labrum from fetal life to old age. J Bone Joint Surg Am 1990;72:1344-8.

2. Park YH, Lee JY, Moon SH, Mo JH, Yang BK, Hahn SH, Resnick D. MR arthrography of the labral capsular ligamentous complex in the shoulder: imaging variations and pitfalls. AJR Am J Roentgenol 2000;175:667-672.

3. Carey J, Small CF, Pichor, DR. In situ compressive properties of the glenoid labrum. J Biomed Mater Res 2000;51:711-6.

4. Sager M, Herten M, Ruchay S, Assheuer J, Kramer M, Jäger M. The anatomy of the glenoid labrum: a comparison between human and dog. Comp Med 2009;59:465-75.

5. De Maeseneer M, Van Roy F, Lenchik L, Shahabpour M, Jacobson J, Ryu KN, Handelberg F, Osteaux M. CT and MR arthrography of the normal and pathologic anterosuperior labrum and labral-bicipital complex. Radiographics 2000;20:S67-81.

6. Cooper DE, Arnoczky SP, O'Brien SJ, Warren RF, DiCarlo E, Allen AA. Anatomy, histology, and vascularity of the glenoid labrum. An anatomical study. J Bone Joint Surg Am 1992;74:46-52.

7. Haynor DR, Shuman WP. Double contrast CT arthrography of the glenoid labrum and shoulder girdle. RadioGraphics 1984;4:411-21.

8. Rafii M. Non-contrast MR imaging of the glenohumeral joint. Part I. Normal anatomy. Skeletal Radiol 2004;33:551-60.

9. Smith JW, Murphy TR, Blair JSG, Lowe KG. Regional anatomy illustrated. Edinburgh: Churchill Livingstone; 1983.

10. Soames R, Palastanga N. Anatomy and human movement: structure and function. 7th ed. Edinburgh: Elsevier; 2018. 593 p.

11. Howell SM, Galinat BJ. The glenoid-labral socket. A constrained articular surface. Clin Orthop Rel Res 1989;(243):122-5.

12. Lippitt S, Matsen F. Mechanisms of glenohumeral joint stability. Clin Orthop Rel Res 1993;(291):20-8.

13. Halder AM, Kuhl SG, Zobitz ME, Larson D, An KN. Effects of the glenoid labrum and glenohumeral abduction on stability of the shoulder joint through concavity-compression: an in vitro study. J Bone Joint Surg Am 2001;83:1062-9. 
14. Robinson A. Cunningham's textbook of anatomy. London: Henry Frowde Hodder \& Stoughton; 1992.

15. Greis, PE, Scuderi, MG, Mohr A, Bachus, KN, Burks, RT. Glenohumeral articular contact areas and pressures following labral and osseous injury to the anteroinferior quadrant of the glenoid. J Shoulder Elbow Surg 2002;11:442-51.

16. Pfahler M, Haraida S, Schulz C, Anetzberger H, Refior HJ, Bauer GS, Bigliani LU. Age-related changes of the glenoid labrum in normal shoulders. J Bone Joint Surg 2003;12:40-52.

17. Drury NJ, Ellis BJ, Weiss JA, McMahon PJ, Debski RE. The impact of glenoid labrum thickness and modulus on labrum and glenohumeral capsule function. J Biomech Eng 2010;132:121003.

ORCID ID:

A. Alashkham 0000-0003-2959-5039;

A. Alraddadi 0000-0002-1526-6608;

R. Soames 0000-0003-1359-172X

deomed.
18. Hata Y, Nakatsuchi Y, Saitoh S, Hosaka M, Uchiyama S. Anatomic study of the glenoid labrum. J Shoulder Elbow Surg 1992;1:207-14.

19. Alashkham A, Alraddadi A, Soames R, Morphometric parameters of the glenoid labrum. European Journal of Anatomy 2019;23:41-7.

20. Smith CD, Masouros SD, Hill AM, Wallace AL, Amis AA, Bull AM. Tensile properties of the human glenoid labrum. J Anat 2008;212: 49-54.

21. McNiesh LM, Callaghan JJ. CT arthrography of the shoulder: variations of the glenoid labrum. AJR Am J Roentgenol 1987;149:963-6.

22. Longo C, Loredo R, Yu J, Salonen D, Haghighi P, Trudell D, Clopton P, Resnick D. Pictorial essay. MRI of the glenoid labrum with gross anatomic correlation. J Comput Assist Tomogr 1996;20: 487-95.

Correspondence to: Abduelmenem Alashkham, PhD, MSc, MBBCh University of Edinburgh, Old Medical School, Doorway 3, Teviot Place, Edinburgh, EH8 9AG, UK

Phone: +44 1316502924

e-mail: abduelmenem.alashkham@ed.ac.uk

Conflict of interest statement: No conflicts declared.

This is an open access article distributed under the terms of the Creative Commons Attribution-NonCommercial-NoDerivs 4.0 Unported (CC BY-NCND4.0) Licence (http://creativecommons.org/licenses/by-nc-nd/4.0/) which permits unrestricted noncommercial use, distribution, and reproduction in any medium, provided the original work is properly cited. How to cite this article: Alashkham A, Alraddadi A, Soames R. Age related morphometric changes of the glenoid labrum. Anatomy 2020;14(3):177-184. 